Postprint of: Bou Franch, Patricia (2011) "Openings and closings in Spanish email conversations." Journal of Pragmatics 43: 1772-1785. doi:10.1016/j.pragma.2010.11.002

\title{
Openings and closings in Spanish Email Conversations
}

\author{
Patricia Bou-Franch \\ Universitat de València
}

\begin{abstract}
Despite the increasing interest scholarly research has shown in the study of computermediated communication, there is still a need to investigate the empirical validity of assumed homogeneity of language usage over the net and focus on the social diversity and variation that characterizes any communication. With this in mind, the present paper is an investigation into the stylistic choices that a particular group of email users made when engaged in a specific activity type. More specifically, it explores the variation in the discourse practices employed to open and close emails in conversation alongside the institutional power of participants and the interactional position of each email contributing to the conversation.

To carry out this study a corpus of short email conversations in Peninsular Spanish was collected $(n=240)$. The analysis focused on the opening and closing sequences of the emails that made up the conversations and considered opening and closing linguistic conventions as discursive practices that members of a community may use strategically. The findings revealed that the discursive practices under scrutiny were subject not only to technological but also to social and interactional constraints and thus highlighted contextual variability. Further, the high degree of sociability in the electronic episodes studied was interpreted as reflecting a "people first, business second" communicative style.
\end{abstract}

\section{Keywords}

Computer-mediated communication, Email, opening, closing, activity type, Spanish

\section{Introduction}

Not long ago a Spanish weekly magazine celebrated the ordinariness of computer use and internet access among Spanish citizens. In line with this reality, finding research papers dealing with the use of language over the net has also become commonplace in specialized communication journals. Computer-mediated research has become more varied and sophisticated as is attested by the recent change in focus from linguistic to discursive frameworks. The latter considers computer-mediated discourses to be subject to technological as well as social constraints (Herring, 2007); however, early research centred primarily on how the technology or the medium in which the communication developed constrained language usage (Androutsopoulos, 2006a) and, additionally, paid little attention to languages other than English (but see Danet \& Herring, 2003; 2007). The present paper develops an analysis of socially-situated electronic conversations in Peninsular Spanish and adopts a discursive and sociopragmatic framework in examining how social and interactional factors shape electronic conversations. This study further considers the role of social variability in computer-mediated interactions. 
In the early days, a strand of computer-mediated communication (henceforth, CMC) researchers attempted to characterise the main features of this mode of communication through descriptions of electronic language, resorting often to comparisons of the former with written and oral face-to-face language and concluding that the language of email was highly informal due to its oral nature (Baron, 1998; Collot \& Bellmore, 1996; Crystal, 2001; Maynor, 1994; Yates, 1996; Yus, 2001). Herring (1996) identified three areas of CMC research, namely, the language of $\mathrm{CMC}$, technological constraints and social constraints on CMC discourse. These early studies, therefore, represent what has been termed the "Internet Linguistics" approach since they share an exclusive focus on the language of CMC but neglect the "second and third research issues, namely the interplay of technological, social, and contextual factors in the shaping of computermediated language practices" (Androutsopoulos, 2006a: 421). Not surprisingly, CMC scholars soon addressed aspects pertaining to interpersonal relations among participants and underscored the sociability of $\mathrm{CMC}$ revealing the central role it plays regarding the establishment and maintenance of social relations (Bunz \& Campbell, 2002; Duthler, 2006; Herring, 1996; Walther, 1996).

CMC research gradually took another step forward by producing more focused, contextsensitive and topic-related studies that considered many of the different medium-related and social-related facets that Herring (2007) identified as relevant to the study of computer-mediated discourse (Androutsopoulos, 2006b; Barron, 2006; Clarke, 2009; de Oliveira, 2003; Duthler, 2006; Ellison et al., 2007; Garcés-Conejos \& Bou-Franch, 2008; Graham 2007; Herring, 1996, 2000; Lange, 2007; Thomson \& Murachver, 2001; Yus, 2007, among many others). These studies view electronic communication as socially-situated discourse and represent the move from medium-related to user-related approaches and from the language of CMC to computer-mediated discourse (Androutsopoulos, 2006a; Herring, 2004; 2007). This move involves underlining social variability and diversity in electronic language usage and focusing on the discourse practices of different social communities.

The present paper studies email conversations produced in an academic context. It seeks to investigate the empirical validity of claims that assume that language usage in emails is homogeneous due its informality and its oral nature. This study identifies the resources that members of a university-based community use when engaged in a particular type of activity and draws attention to the stylistic variation derived from the influence of two contextual factors (i) the power of email users understood in terms of their institutional position within the community; and (2) conversational progression, i.e. discourse variation taking into account the position of each email message in the conversation.

To carry out this study a corpus of short email conversations in Peninsular Spanish was collected. The analysis focused on the opening and closing sequences of all the emails that made up the conversations and examined the ways in which social and interactional 
factors - besides technological ones - influenced the discursive practices used by members of a community to open and close emails.

\section{Background}

In order to study the effects of social and interactional constraints on technologymediated conversations a sociopragmatic approach was adopted, the main aim of which is to understand language within the activity type or social episode in which it is used. The main reason for adopting such an approach lies in the belief that only under such socially-sensitive, discursive constructs can we highlight the social diversity underlying computer-mediated communication. Levinson (1992:69) defined an activity type or social event as "a fuzzy category whose focal members are goal-defined, socially constituted, bounded, events with constraints on participants, setting, and so on, but above all on the kinds of allowable contributions." An advantage of this definition is its broad scope and, therefore, its ease of applicability. Levinson further proposed to divide activity types into structural episodes and stylistic resources adapted to the goal of the activity (Levinson, 1992: 69-71).

As mentioned before, the object of this paper is to conduct a sociopragmatic study of email conversations. But, what do we know so far about email communication? Androutsopoulos claims that "it is empirically questionable whether in fact anything like a 'language of e-mail' exists, simply because the vast diversity of settings and purposes of e-mail use outweigh any common linguistic features" (2006a: 420). While generally agreeing that there is no universally valid language of email, it is worth revising what we know about the structure and style of email interaction in order to discover recurring versus situation-specific patterns.

One of the main shortcomings of studies of email interaction is that emails have mainly been investigated as individual (isolated) instances of communication as opposed to emails in a dialogue, that is, emails that are part of ongoing albeit asynchronous conversation. Baron (1998: 142), for example, set out to investigate "CMC as one-toone dialogue with identified interlocutors" but, despite using the word "dialogue" to refer to her data, she never pursued the study of the interactional features of email conversations.

The present paper seeks to remedy the structural weakness of prior research by focusing on email conversations and by singling out an important interactional constraint: the initial or non-initial position of emails within a conversation (Sinclair \& Coulthard, 1975). Although some scholars mention the possible influence that email position within the conversation (specifically whether it is the first communication or not) may have on discourse choice (Bou-Franch, 2006; Crystal, 2001; Waldvogel, 2002), this aspect has only been tackled in Waldvogel's (2007) large-scale study of email openings and closings. This author distinguished initiating from follow-up emails but found that this had no effect on the use of opening greetings. 
Another aspect relating to the structure of this activity type or social episode is the internal organisation of each email into three parts: openings, topical sequences or body and closings (Baron, 1998, Bou-Franch, 2006; Crystal, 2001; Herring, 1996; Waldvogel, 2002, 2007, among others). The structural elements of emails may be optional or obligatory: the obligatory element contains the body of the message while the greetings and farewells constitute the optional segments.

Here I focus precisely on the optional elements of emails: the opening and closing sections or sequences. These are mainly phatic, interpersonally-loaded structural slots, mostly empty of content regarding the goal or reason for the interaction. While in opening sequences the social relationship between participants is negotiated and established, or recalled, in closing sequences participants work to accomplish a joint, negotiated, frictionless termination of the social event (Schegloff \& Sacks, 1973; Albert $\&$ Kessler, 1978). Given the optionality of opening and closing sequences, empirical research should uncover the contextual (technological, social, interactional) conditions that constrain their presence and absence as well as their shape. However, this cannot be done without simultaneously addressing the second component of an activity type or social event, that is, the style in which it is conducted (Levinson, 1992).

Although recurring patterns were identified for the first component - structure - of the activity type, the same cannot be said of this second component - style - since only user-related, socially-situated analyses can reveal and explain the stylistic choices that communities of email users make in particular social settings. It is here that Androutsopoulos' (2006) contention to the effect that there is no homogeneous and unique "language of email" takes on full meaning.

The works of Sherblom (1988), Waldvogel (2007), Pérez Sabater et al. (2008) and Bou Franch (2006), among others, show the interplay of structural and stylistic features in email openings and closings. On the one hand, Sherblom (1988) examined the influence of social position within a hierarchy on the use of signatures in a corpus of emails received by a manager in a large business organisation. The data showed that none of the messages sent down the hierarchy was signed while over a third of messages sent to superiors contained signatures, which led Sherblom (1998) to conclude that signature use reflects and builds power relations. On the other hand, Waldvogel (2007) collected email data from two workplaces: an educational organisation and a manufacturing plant and carried out a detailed discussion of greetings and closings vis-à-vis sociological variables of participants such as relative status, social distance and gender as well as interactional distinctions between initiating and responding or follow-up emails. Waldvogel (2007) unveiled that through their choice of greetings and closings email users contributed to the formation of what she termed workplace culture. This implied indirect and socially distant styles of communication in the educational organisation and direct, friendly and familial styles in the manufacturing plant. Further, Pérez Sabater et al. (2008) explored orality and informality in a corpus of international academic 
exchanges and found that one-to-one emails incorporated more informal conversational traits than emails sent to a group. This was especially evident in the greetings and farewells of the emails and highlighted stylistic differences. Finally, Bou-Franch (2006) explored the interpersonal styles of deference and solidarity in the opening, requesting and closing sequences of a contextualised corpus of emails in Spanish sent by students to their university lecturers. The analysis brought to the fore the importance of sociability in this social and electronic context and, more specifically, in the opening and closing sections, since most emails in this study contained opening sections while all of them had closing moves. This seemed to be contrary to most research on email interaction which shows that email messages tend to be shorter, often "dispensing with ... opening and closing routines" (Baron, 1998: 159. See also Crystal, 2001; Herring, 1996; Sherblom, 1998; Waldvogel, 2002, 2007). This finding, thus, motivated the present, larger, study.

The general goal of the present study is to empirically investigate prior claims that discourse practices in particular types of online communication are homogeneous due to the supposedly oral and informal nature of the interaction. It also seeks to analyse the stylistic choices that a particular group of email users make when engaged in a certain activity type. More specifically, this paper investigates whether the institutional power of participants and email position across the interaction influence the occurrence and shape of opening and closing discourse practices. The following research questions guided the empirical study that follows.

Research question 1: Do opening and closing practices vary depending on the institutional power relationship between email users?

Hypothesis 1: Since power is considered one of the single most important sociological factors influencing discourse (Van Dijk, 1989) and, more specifically, given that prior research has found that signatures, a closing mechanism, vary according to the hierarchical power between participants in the electronic exchange, it was hypothesized that discourse style regarding openings and closings would vary vis-à-vis institutional power.

Research question 2: Do opening and closing practices vary as the conversation unfolds, i.e. depending on the initial or otherwise position of an email within the conversation?

Hypothesis 2: Waldvogel (2007) seems to be the only study that empirically examined this aspect of email conversations: her findings revealed that greetings did not vary from initial to responding emails. However, the data of Waldvogel's study were noticeably different from the electronic data of empirical studies conducted with Peninsular Spanish (Bou-Franch, 2006; Bou-Franch \& Lorenzo-Dus, 2008) in that the former contained far fewer opening and closing mechanisms than the latter. Following some researchers' claim that opening and closing devices are frequently absent from email interaction (Baron, 1998; 
Crystal, 2001; Herring, 1996; Sherblom, 1998; Waldvogel, 2002, 2007), it was hypothesized that the initial or non-initial position of the email message in the conversation would affect the occurrence and shape of opening and closing practices in the data.

\section{Methodology}

\subsection{Data}

In order to answer the two research questions above, a corpus of 100 short email conversations comprising a total amount of 240 individual emails was compiled. All electronic conversations were spontaneously generated and took between one and eight days to be completed. The conversations were provided by eight lecturers at the university where the author works.

The email conversations were the discursive product of two different but comparable activity types or social episodes, one involving communication between university lecturers ( $\mathrm{n}=50$ conversations) and the other involving communication between undergraduate students and their lecturers ( $n=50$ conversations). Comparability was granted by the fact that the conversations took place in the same institutional setting the university - that imposed constraints on the role and identity of participants as well as on the content and manner of the communication, and, more importantly, by the fact that both episodes shared the same functional goal, namely, all conversations contained an initial institution-related request that was subsequently addressed in the interaction.

The data consisted of either two email exchanges $(n=60)$ or three email exchanges $(n=$ 40). In all cases, the email that initiated the exchange contained a request. In addition, in the case of student-lecturer electronic exchanges, it was always the student that initiated the interaction.

The discursive data used in this study is subject to medium (technological) and situation (social) constraints (Herring, 2007). An important medium-related aspect of the data is its asynchronous nature. Since any response to an initiation or any comment to a prior response will be delayed, each contribution to an electronic exchange may be seen as having a seemingly independent nature and may contain its own opening and/or closing sequence. Unlike face-to-face or telephone conversations, in which opening and closing sequences frame the whole encounter, in email exchanges each individual contribution may also be framed by these discourse sequences, as if acknowledging the temporal 'interruptions' derived from the asynchronous nature of the interaction.

On the other hand, an important social aspect of the discourse practices under study lies in their institutional character. The institutionality of the data "is constituted by participants through their orientation to relevant institutional roles and identities ... and through their production and management of institutionally relevant tasks and activities" (Drew \& Sojornen, 1997: 94). In the data, the institutional roles of 'student' and 'lecturer' were salient since all the emails in the corpus were written for work- 
related purposes, thus highlighting their institutional character. This had important consequences for the establishment of power relationships among participants in the electronic conversations, as will be seen below.

\subsection{Procedure}

Drawing on computer-mediated research (Herring, 1996; 1999; Crystal, 2001; BouFranch, 2006), conversation analysis (Jefferson, 1972; Schegloff \& Sacks, 1973) and discourse analysis (Sinclair \& Coulthard, 1975; Stubbs, 1983), the sequence and the move were adopted as structural units of analysis. Opening and closing sections or sequences contain moves, the basic unit of analysis, defined as the minimal functional discourse unit. Sequences are, therefore, larger units of moves bound together by their topical or functional coherence (Jefferson, 1972; Stubbs, 1983; Herring, 1996).

Electronic sequences of moves are both, interactional - in the sense that the moves set up or satisfy expectations - and asynchronous.

With a view to studying the occurrence and shape of the opening and closing discourse practices of all emails alongside the power-based relationship of participants, on the one hand, and the progression of the electronic conversation, on the other, it was decided to carry out four levels of analysis:

(1) Frequency of occurrence of opening and closing sequences in each email;

(2) Density of opening and closing sequences, as reflected in (i) the mean number of words and (ii) the mean number of moves that the said sequences contained (Bou-Franch \& Lorenzo-Dus, 2008);

(3) Type and frequency of occurrence of opening and closing moves; and

(4) Expression of familiarity and distance in the greeting and the leave-taking.

The moves identified in the opening sequences of the data included the greeting, selfidentification and the personal comment. In closing sequences, expressions of gratitude, good wishes, leave-taking, apologies, pre-closings, self-identifications, signatures and postscripts were found. However, considering the wealth of data and the four-level analysis to be carried out, there emerged the need to focus on the most representative moves and so it was decided to analyse only the moves that appeared at least $50 \%$ of the time in any of the data subsets. This left greetings and self-identification moves in opening sequences and thanking, leave-taking and signatures in closing sequences. Table 1 illustrates the most representative moves. Throughout this paper, examples have been anonymized by using fictitious personal names and course modules.

*** Please insert Table 1 about here ***

At this point, and given the emphasis that this study places on social diversity and variability, it is worth noting that leaving out less frequent moves should not be viewed as reproducing ideas about homogeneity regarding opening and closing discourse practices. This paper focuses on recurrent discourse patterns of email communication in 
a particular, situated social episode and therefore presupposes context sensitivity and expects variability; in contrast, overgeneralizations regarding email moves independently of the context in which emails are produced presuppose homogeneity i.e. all emails are the same, and do not allow for social (or any type of) variability. Example 1 below illustrates some of the less representative closing moves. It displays an initiating email from a student to her lecturer that contains two infrequent closing moves: an apology (...and I'm sorry for any inconvenience) and an expression of good wishes (... and have a good summer).

\section{Hola Beatriz [Hi Beatriz]}

(request)

Muchas gracias por todo y siento las molestias. [Thank you very much for everything and I'm sorry for any inconvenience]

Un saludo y que vaya bien el verano! [Regards and have a good summer]

Example 1. An illustration of less representative moves

Finally, greeting and leave-taking moves, which are generally considered "as the most salient structural features of an email" (Pérez Sabater et al., 2008: 76), were selected for further analysis. Informal, direct moves such as Hola María [Hi María] or Hasta pronto [See you soon] were analysed as discourse practices expressing closeness, involvement and familiarity. In contrast, moves such as Estimado Dr Pérez [Dear Dr Pérez] or Un cordial saludo [Kind regards] were taken to function as distancing mechanisms oriented towards deference and independence (Brown \& Levinson, 1987; Scollon \& Scollon, 1995; Waldvogel, 2007).

In order to answer research question 1, concerning the effect of power relations on openings and closings, the data were divided into two subsets that considered the institutional power of participants and recognised two power-based groups. One group involved 50 conversations between university lecturers. These were named the equal encounters since participants in these exchanges were seen as having the same power relative to their institutional role (Example 2); the second group contained 50 conversations between students and lecturers, and these were considered the unequal encounters given the more institutionally powerful role of the lecturer over the student (cf. Van Dijk, 1989) (Example 3). During the analysis, results were also computed considering communication to equals and emails sent up and down the institutional hierarchy.

It must be noted that participants in both activity types also had offline contact in a series of different events within the institution such as, for example, the classroom or tutorials where students coparticipated, or department meetings where only lecturers were involved. Therefore, far from being anonymous, participants were identified email users with a shared interpersonal history (Mills, 2003) whose communicative parameters may be carried over from the offline to the online interaction (Herring, 2003). 
Querida Isabel: [Dear Isabel]

(This lecturer requests to meet to discuss certain matters)

Un abrazo, [A hug]

Pedro

Responding email:

Hola Pedro: [Hello Pedro]

(Reply)

Un saludo, [Regards]

Example 2: Equal encounter

Initiating email

Hola Paco: [Hello Paco]

Soy Marta Fernández Gómez, alumna de su asignatura Biología I [I am Marta Fernández Gómez, a student of your module Biology I]

(This student requests permission to write a paper together with another student)

Gracias por su atención, [Thanks for your attention]

Que tenga un buen dia, [Have a good day]

Marta Fernández

Responding email:

(No opening)

(Reply)

Un saludo, [Regards]

Paco

Example 3: Unequal encounter

In order to answer research question 2 regarding openings and closings vis-à-vis conversational progression, and since conversations were made up of multiple emails, it became necessary to identify the place of each email within the said conversations. The short conversations in the corpus contained either two emails (one requesting and the other responding to the request) or three emails (an initial request, a second responding email and a follow-up, usually thanking, email). Accordingly, the corpus of this study was further divided into two data sets comprising (1) the two email exchanges and (2) the three email exchanges (henceforth $2 \mathrm{EM}$ and $3 \mathrm{EM}$, respectively). The $2 \mathrm{EM}$ data set consisted of 60 conversations, that is, 120 emails, while the $3 \mathrm{EM}$ data set contained 40 conversations totalling 120 emails. During the analysis the results were also computed for initial and non-initial emails.

In summary, the 50 equal encounters as well as the 50 unequal ones were divided into 2 $\operatorname{EM}(n=30)$ and $3 \mathrm{EM}(\mathrm{n}=20)$ exchanges.

\section{Results and Discussion}

\subsection{Occurrence of opening and closing sequences}

The first step in the analysis was to compute the occurrence of opening and closing sequences in all data sets. Tables 2 and 3 show the results of the count broken down into $2 \mathrm{EM}$ and $3 \mathrm{EM}$ exchanges, respectively. The findings were further divided into equal 
and unequal encounters and, within these, into initiation, response and, where appropriate, follow-up emails (Sinclair \& Coulthard, 1975; Stubbs, 1983).

*** Please insert Table 2 about here ***

*** Please insert Table 3 about here ***

The most outstanding finding was the very high frequency of occurrence of both opening and closing sequences in the data. The number of openings was found to decrease as the conversation unfolded in all data sets: equal and unequal 2 EM and 3 EM exchanges. Closings, however, did not always decrease (e.g. 2 EM unequal encounters) and when they did, the tendency was to decrease only slightly.

Previous research has underlined the optionality of opening and closing sequences and their generalised absence from electronic interactions, which is usually attributed to the informality of the medium (Baron, 1998; Crystal, 2001; Herring, 1996; Maynor, 1994, Yus, 2001). However, openings and closings were pervasive in the social events under study: openings had an overall representation of over $85 \%$ while closings were even more frequent, appearing in $97 \%$ of all emails. This finding contrasts sharply with prior research. For example, Waldvogel (2007: 7) found that of the emails produced in the educational organisation she examined, only $59 \%$ contained greetings while $34 \%$ had closings. The numbers for the manufacturing plant were even lower: only $17 \%$ of emails had greetings and $10 \%$ had closings.

The ubiquity of opening and closing sequences in the data could be interpreted as resulting from institutional and cultural constraints. In a study dealing with methodological aspects of cross-cultural pragmatics research, Bou-Franch and LorenzoDus (2008) compared requests from elicited data and from spontaneously generated emails. The electronic data in this study consisted of emails sent by students to their university lecturers in a British and a Spanish university. A look at their analysis reveals that over 77\% of the British English and 93\% of the Peninsular Spanish emails contained opening mechanisms while all of them had closings in both languages. This study, therefore, lends support to the interpretation that the pervasiveness of the sequences was due to the institutional context of the communication. More research, however, should be conducted to further confirm this line of argument and also to establish the weight of cultural context in these discourse practices.

To have a clearer picture of the influence of institutional power on the use of opening and closing sequences, these were reorganised as (i) emails between equals; (ii) emails sent up and (iii) emails sent down the hierarchy. As can be seen in table 4, the number of opening and closing sequences was surprisingly similar in all cases, the only exception being the opening of emails sent down the hierarchy which contained somewhat fewer sequences.

*** Please insert Table 4 about here *** 
In general, frequency of use of opening and closing practices was not significantly affected by the power relationship between email users. In this respect, prior findings have been contradictory. On the one hand, Sherblom (1988) found power and status to have an influence on the use of a closing mechanism while, on the other, Waldvogel (2007) obtained different results regarding the influence of status. Status affected the data differently, depending on the setting: status played a role in the educational organisation but not in the manufacturing plant, and this was attributed to the different workplace cultures underlying communication.

Regarding the effect of conversational progression on opening and closing sequences the data were regrouped into initial and non-initial emails. The findings revealed that initial emails contained more opening sequences than non-initial messages, while there was scarcely any variation in the frequency of use of closing sequences (Table 4). Conversational progression, then had an effect on the number of opening sequences, more specifically, the opening mechanisms of the longer 3 EM conversations exhibited a clearly decreasing pattern (Table 3 ). In contrast, it had no effect on the frequency of use of closing sequences.

\subsection{Density of opening and closing sequences}

Next, the density of opening and closing sequences was considered in terms of the mean number of words and moves in all the emails in the corpus. The mean number of words and moves was obtained by dividing the total number of words or moves into the total number of opening or closing sequences of the corpus. The findings revealed that opening sequences were less dense than closing sequences regarding both words and moves. This implies that the email users in the data were more direct when opening the message and did more work when closing it.

Table 5 shows that the density of both opening and closing sequences in 2 EM encounters decreased from the initiation to the response email, both in equal and unequal encounters. The decreasing pattern of density was most pronounced regarding number of words in the opening sequences of all 2 EM exchanges.

*** Please insert Table 5 about here $* * *$

In the case of 3 EM exchanges (Table 6), the density of opening and closing sequences regarding both words and moves was found to decrease from the initial email to the responding email in equal and unequal encounters. Follow-up emails tended to increase their density (in terms of words) with respect to the previous, responding emails and exhibited a tendency to maintain the same density (in terms of moves) as the responding emails. It may be argued that in responding to a request, less dense contributions would be expected. 
A look at the findings vis-à-vis institutional power (Table 7) revealed that the sequences under analysis were nearly equally dense in terms of moves. Density in terms of words, however, varied depending on institutional power. The data showed that openings were considerably denser in emails sent up the hierarchy than in emails sent down or emails to equals. Openings to equals, in turn, were also found to be denser than openings sent down the hierarchy. On the other hand, closings sent to equals were the densest while closings sent down the hierarchy were the least dense. This indicates that the less institutionally powerful email users were more verbose in addressing the more powerful receivers; the latter, in turn, were more direct and used less verbosity in addressing nondominant users. However, in addressing equals lecturers used the densest closing remarks probably due to institutional conventions related to professional respect. Overall, closings exhibited greater density than openings in all counts.

A closer inspection of density alongside conversational progression (Table 7) revealed that initial sequences were always denser than their non-initial counterparts. However, the degree of variation was not always the same. The greatest difference was found when considering density in terms of words. In such cases, both the opening and the closing were denser in initial than in non-initial positions. Sequence density in terms of moves also tended to decrease in non-initial positions although the difference was small. Finally, closing sequences were globally denser than opening sequences in both positions.

*** Please insert Table 7 about here ***

In sum, the density of opening and closing moves proved to be affected by both institutional power and conversational progression. The picture that emerged in combining both variables showed the opening sequence of initial emails sent up the hierarchy exhibited greatest density and the closing sequence of non-initial emails sent down the institutional hierarchy displayed the least density. This indicates that the email users in the corpus were especially careful in elaborating their comments in order to begin conversations, particularly when addressing users of higher institutional standing. In contrast, a more casual, less elaborated style seemed appropriate in closing conversations with non-dominant users. The following analysis of the frequency of occurrence of the moves within the sequences may further help to explain these results.

\subsection{Frequency of opening and closing moves}

This analysis concerned the frequency of occurrence of opening and closing moves in the data (tables 8 and 9). As can be observed, the greeting proved to be the most common move in the opening sequence in online conversations of all lengths regardless of the institutional identity of participants. Greetings were slightly less frequent in emails sent down the hierarchy (table 10); this finding partly confirmed prior research that revealed a tendency to include a greeting in messages sent up the hierarchical line (Waldvogel, 2002; 2007). 
Additionally, greetings revealed decreasing patterns in frequency of occurrence from the initial to non-initial position (table 10); more specifically, they were found to decrease in number from initial to responding and, where applicable, also to follow-up positions. Decreasing patterns were maintained in both equal and unequal encounters. This means that although users were aware of the interruptions that accrued from the asynchronous nature of the communication, which led them to make frequent use of openings and closings, they were also sensitive to the interactional context and decreased their use of these mechanisms in each new contribution. In this sense, Waldvogel (2002) found greetings only in $40 \%$ of the data, an amount that coincided with the number of first contributions on a topic. For this reason she suggested the need "to see whether the greetings belong mainly to the first communication" (2002: 47). The author took up this task in Waldvogel (2007: 7) but found that the fact that emails were the first or responding message had no effect on use of greetings. In contrast, nearly all the first contributions in my data contained greetings, and decreasing patterns were found as explained above. However, most second and many third and final contributions also contained greetings, and their occurrence was always higher than the $40 \%$ of Waldvogel (2002). This author explained her data by reference to the type of workplace in which it developed, which she characterised as having a "get down to business straight away" nature. What seems evident is that this type of behaviour does not apply to the social episodes under scrutiny here, in which senders nearly always took the time to do interpersonal work via use of greetings.

\footnotetext{
*** Please insert Table 8 about here $* * *$

*** Please insert Table 9 about here $* * *$
}

The other opening move, the self-identification, was found to be exclusively used in emails that initiated the interaction and it proved to be much more frequent in unequal than in equal encounters; more specifically, self-identifications were mainly used in emails sent up the institutional hierarchy. Emails sent down the hierarchy contained no such moves and they were hardly present at all in emails sent to equals. The high occurrence of this move in students' initial communications was considered to partly explain the sharp contrast obtained between the markedly greater density of initial emails and the much less dense non-initial emails (see section 4.3. above). The effect of institutional power and conversational position may be explained by the technical and situational context of the communication. First, students in the university where the data were collected are given an email address that consists of an acronym made up of the first syllable of their first and last names; therefore, unless they self-identify through other means, their lecturer does not know who they are. Second, even after providing their names, there are usually so many students in a classroom that lecturers may still not recognise them. This forces them to also indicate what course they are taking with a particular teacher. In sum, through self-identification moves students show an awareness of the restrictions surrounding their technological account and, in adapting their situation to the medium, they make explicit the type of relationship they have with 
the receiver, orienting their talk to the institution and constructing their institutional identities in discourse. Finally, once an email user has self-identified at the beginning of the interaction, there is no need to further repeat their identity in subsequent contributions, hence their initial-only position.

Closing sequences proved to be more complex and elaborate, with three moves showing special relevance: thanking, leave-taking and signature. With regards to thanking, the findings showed their use decreased from the initial to the final email of $2 \mathrm{EM}$ equal and unequal encounters. In $3 \mathrm{EM}$ exchanges, they had greater representation in the initial email; this decreased greatly in the intermediate, responding email and then was constant in the follow-up move of equal encounters while it increased considerably in the final email of unequal encounters.

*** Please insert Table 10 about here ***

A detailed account shows that emails sent up the hierarchy contained eight times more thanking moves than emails sent down (cf. Waldvogel, 2002). Two factors seem to play a role in this finding: on the one hand, students showed that they were aware of their role as the institutionally non-dominant participant and thus chose expressions of gratitude to show deference and respect. On the other hand, in all unequal encounters students were in the requesting position. Since requests are rapport-sensitive acts (Spencer-Oatey, 2000) and may be viewed as imposing on the receiver, requesters were prone to use more thanking moves to mitigate and compensate for the imposition. Emails sent down the hierarchy hardly contained thanking moves. However, this does not mean that lecturers do not usually employ this move, rather, their position as request respondents constrained their contributions; so, in responding to a request expressions of gratitude towards the requester were not expected in this socio-cultural context. Furthermore, it must be mentioned that emails sent to equals contained over three times as many thanking moves as emails sent down. In emailing equals, lecturers were in both functional roles: requester and request respondent. The finding that initial (requesting) emails contained more than twice as many expressions of gratitude as non-initial (responding and follow-up) emails confirms that conversational position constrained acceptability, that is, 'allowable contributions' (Levinson, 1992), in virtue of the different function that emails performed in each position. Further, the amount of thanking moves in initial emails also shows users' adaptation to the medium (Herring 2007). While in face-to-face interaction the request would be immediately followed by a response and then by a thanking move, in email interaction users, aware of the asynchrony underlying the communication, felt the need to thank in advance, thus adapting to the technology used.

In contrast with previous studies which found farewells to be minimally present (Herring, 1996; Waldvogel, 2002), the leave-taking move was abundantly represented in the data under study, appearing in over $75 \%$ of the emails of nearly all the data subsets. The leave-taking move exhibited a high frequency of occurrence in $2 \mathrm{EM}$ 
exchanges, with little variability vis-à-vis institutional power or conversational progression. A process of accommodation in which senders of second contributions mirror the closing conventions of first contributions may have been at work in these short interactions (Bunz \& Campbell, 2002; Crystal, 2001). In 3 EM exchanges, however, leave-taking moves were found to be more frequent in the middle emails than in the initial or final mails. Leave-taking moves were least frequent in emails sent up the institutional hierarchy thus showing students to be the most infrequent users of this move. In contrast, communication between equals, i.e. lecturers, showed the highest frequency of this move. This may evidence that institutional conventions affect lecturers and students differently in that lecturers are expected to maintain a certain degree of formality with equals in the professional context. Finally, the leave-taking increased from initial to non-initial contributions only slightly, so conversational position was not considered a determining factor.

Finally, signatures were the most common closing move in the data. In all unequal conversations, they were less frequent in emails sent by students, that is, emails sent up the hierarchy contained the lowest number of signatures. This finding was seen to interact with the high presence of self-identification moves in the same group of emails. If students already identified themselves in a detailed way in the opening they probably viewed signatures as redundant and unnecessary. In contrast, frequency of use of signatures was hardly influenced by the position of the email in the conversation.

\subsection{Expression of familiarity and distance}

Finally, the analysis focused on the expression of familiarity and distance in a representative move from each sequence, i.e. the greeting and the leave-taking. The study related the discourse practices or language resources used in these moves to their interpersonal meanings broadly divided into expressions of (i) familiarity, involvement and closeness - rapport-building actions (positive politeness) - or (ii) expressions of distance, independence and deference - respect-building actions (negative politeness) (Brown \& Levinson, 1987; Scollon \& Scollon, 1995; Spencer-Oatey, 2000). Through variation in the use of the above mentioned opening and closing practices, email users exchanged interpersonal messages and conveyed social information in otherwise institutionally task-oriented messages. As Waldvogel (2007:3) puts it:

In as much as greetings and closings pay attention to the recipient and are oriented to the addressee's face needs ... they are politeness markers. Like other politeness markers, they serve an important function in constructing and maintaining workplace relationships. Greetings and closings enable the writer to express warmth or distance, expressions that are otherwise difficult to do in email, and they are a strategy for personalizing messages as well as a means of reinforcing status relationships and underlining social expectations.

\footnotetext{
*** Please insert Table 11 about here $* * *$

*** Please insert Table 12 about here $* * *$
} 
In computing the results of the analysis, the percentage was used to show the distribution of one move into expressions of familiarity and expressions of deference (tables 11 and 12). The greeting was found to be used to express closeness and familiarity in all the emails of unequal encounters whereas the greetings of equal encounters showed more variation in their social meanings. A closer inspection of the data revealed that emails sent up and, especially, sent down the hierarchy favoured familiarity and closeness, whilst greetings between equals displayed as much familiarity as distance (table 13). The offline dynamics of increasing camaraderie in the lecturerstudent relationship within the Spanish classroom context may have biased discourse practices towards rapport-building expressions (Márquez Reiter et al., 2005). Moreover, these expressions created a sense of fake/feigned (as opposed to actual) confianza or intimacy. Spanish scholars view confianza as the most important, culture-specific way of enacting familiarity patterns or affiliation between friends in the Spanish cultural context and identify cases of fake/feigned confianza underlying relations between more distant participants (Bravo, 1999; Hernández Flores, 1999; Albelda, 2007). In our data, the situation of fake/feigned confianza or familiarity in the lecturer-student relationship could be explained by the continuous classroom interaction. This underlines the importance of continuous contact that may at times supersede expected formalities derived from the institutional power imbalance.

On the other hand, institutionally dominant participants' use of both close and distant greeting practices revealed that although lecturers may perceive each other as equals, they were cautious in their social relations so as not to incur in excessive familiarity and showed an appropriate amount of professional respect, which is a norm within the institution.

Regarding conversational position, the data showed a clear pattern towards greater familiarity from initial to non-initial email groups (Table 13). This implies that unequal conversations reinforced their rapport-building practices whereas lecturers in equal encounters changed their strategy from attempts to avoid friction and maintain a respectful distance to negotiated use of closer and warmer expressions.

*** Please insert table 13 about here ***

Finally, the sociability of leave-taking practices was assessed. The leave-taking move exhibited a marked preference for the expression of distance and respect in all email groups. This preference for distancing mechanisms was kept constant alongside participants' institutional power and only showed a slight move towards somewhat less deference in contrasting initial and non-initial email sets. Summing up, although power and conversational position played significant roles in the social meanings of greetings, they did not have an impact on the social meanings conveyed by farewells, which generally showed patterns of respect-building practices. Therefore, while more familiarity was allowed in conversational beginnings, endings took on an air of distance 
and deference which was probably considered socially suitable after performing an impositive action like requesting.

Going back to the two research questions that guided this analysis, the findings confirmed the two hypotheses that were formulated since both, the social variable regarding the institutional power relationship between email users and the interactional variable regarding the position of each email within the conversation had an influence on the presence/absence as well as on the shape of opening and closing discursive practices. On the one hand, power was seen to affect most of the features under study. Emails sent down the hierarchy stand out as being markedly affected by power patterns, since they contained the least dense opening and closing sequences, the smallest number of greetings, self-identifications ad thanking moves and also exhibited greatest familiarity in the greetings. This indicates that in emailing non-dominant participants, less elaborated forms of sociability were expected and the formal norms within the institutional setting appeared to be more relaxed. It must be noted, however, that emails sent down the hierarchy were always responses to requests, which also played a role in the more numerous informality patterns. On the other hand, the findings revealed that email position also affected nearly all aspects of email communication under scrutiny. In comparing initial and non-initial emails, decreasing patterns were found in the frequency of occurrence of opening sequences, in the amount of density and in the number of greetings, self-identifications and thanking moves. A pattern of increasing familiarity in the greeting also surfaced in comparing initial and non initial emails. The findings reveal a general tendency towards less elaboration and more intimacy; as the interaction unfolds, users seem to perceive less need to do complex interpersonal work through openings and closings and, after breaking the ice in the initial contact, negotiate their relationship towards greater informality.

In all, the patterns reveal that users were sensitive to the technological, social and interactional parameters surrounding their contributions and varied their style accordingly. The data place a strong emphasis on the role of variability in electronic communication. Further research should take this fact into account and treat emails differently according to these parameters. Also, other sociolinguistic factors influencing electronic discourse should be investigated.

Alongside variability, the data also brought to the front the importance of sociability in these communications. In the next section, these aspects are further discussed and their relation to email communicative style is established.

\section{Variability, sociability and communicative style}

The variability found in this empirical study of emails questions the validity of claims of homogeneity of language use over the internet and points to the fact that the 'language of email' (Baron, 1998; Crystal, 2001; Maynor, 1994, Yus 2001) does not exist as a set of linguistic features underlying all email communication. Therefore this 
study lends support to Androutsopoulos' (2006a) suggestion that there is a need to demythologize the homogeneity of email communication; this paper further contributes to highlight the ways in which email conversation is affected by the diverse social parameters under which it is produced.

The language of emails has generally been described as oral and informal due to its conversational immediacy, and these features have often been used as arguments for claims regarding the general absence of openings and closings from this communication (Baron, 1998; Crystal, 2001; Maynor, 1994). However, this paper provides evidence of the pervasiveness and diversity of opening and closing mechanisms in certain situated email practices and therefore shows that the assumption that all email communication is the same, i.e. homogeneous, informal and generally lacking openings and closings, is untenable.

The results also highlight the way in which email structure and style interact and, although the focus of this paper was on user-related aspects of CMC, the influence of the technological features of the medium, and more specifically, the role of asynchrony, was also acknowledged (Herring, 2007). The present socially-situated study underlined the multiple technological, social and interactional influences that simultaneously play a role in shaping the structure and style of email discourse practices. Further research should acknowledge the need to position electronic discourse within the broader sociocultural context in which it is produced and to tease out the many contextual influences affecting variability.

In this respect, interesting issues regarding social variables emerged during the analysis. More specifically, the finding that equal encounters were more deference-oriented than unequal conversations - where the opposite may have been expected - suggested a need to problematise power-related categories such as 'equal'/'unequal' (Scollon \& Scollon 1995). A casual conversation between friends constitutes an equal encounter necessarily different from a work-related conversation between colleagues. Furthermore, within the latter equal encounters, the discourse practices of lecturers negotiating the where and when of the departmental Christmas dinner will in all probability differ from the practices of the same lecturers negotiating the future of the Departments' research programme. Therefore, the status of equal institutional power should be considered as interacting with other issues like the imposition of the topic under discussion, or the presentation of, and need for recognition of, one's professional identity at a given moment. This calls for more research into further social aspects influencing email interaction and the way in which these interact. Additionally, considering that identity issues are in constant flux and are constructed in discourse (De Fina et al., 2006), quantitative analyses like the one presented here could complement qualitative approaches that allow for subtle, nuanced differences to be captured more effectively and for a focus on discursive processes like identity construction within an institution. 
Finally, the ubiquity of opening and closing discourse practices was taken to mean the foregrounding of sociability in the episodes under study. Since discourse practices contribute to create and simultaneously reproduce the communicative style of social episodes, sociability was interpreted as a landmark of the communicative style of this university-based community. In contrast, in her study of emails in an educational context, Waldvogel (2007) argued that the systematic absence of greetings and farewells in her data represented a "business first, people second" email style (Waldvogel, 2007: 17). Thus, the emphasis on sociability in the episodes under study could represent the exact opposite type of email style described above: a communicative style characterised by a "socialise first, get to the point and socialise again" attitude, and, therefore a "people first, business second" email style.

It must be noted that, although this paper did not focus on culture-specific influences, the highly sociable communicative style of the email conversations in the data is in line with findings from Hispanic scholarly research (Márquez Reiter et al., 2005; Albelda, 2007) which stress the importance of the social notion of simpatia (broadly speaking, friendliness) as a means of building interpersonal relations in Peninsular Spanish contexts. The email communicative style "people first, business second" could also be an example of the value Spaniards have been found to place on being appreciated and liked by other participants in the social event, and to, therefore, come across as simpático (friendly). Further research should examine not only technological and social diversity in communication but also the influence of the larger cultural contexts of the communication. This would also prepare the way for cross-cultural investigations of email discourse practices, an issue deserving more attention.

\section{Conclusion}

I opened this paper with an allusion to the ordinariness of computer use and internet access among Spanish citizens. Underlying the ordinarization of computer use in any society, we find a process of technological popularization at work. Through this process, an increasingly large number of individuals gain access to the internet and put email to extended uses in social, professional and academic settings. At present, email communication takes place between a wide range of users, for different communicative purposes and in numerous contexts. Not surprisingly, in an introduction to a volume on sociolinguistics and computer-mediated communication, Androutsopoulos (2006a) set the agenda of CMC scholarly research for the coming years. He called researchers to focus on "the role of linguistic variability in the formation of social interaction and social identities in the internet" (2006: 421), which involves exposing the impossibility of the existence of a (unified) language of emails and underlining the social diversity of language usage in CMC. This paper follows Androutsopoulos' (2006a) agenda and represents a move away from the language of internet to the study of socially-situated, computer-mediated discourse. By highlighting the social variability and diversity that surrounds email communications, this paper hopes to contribute to moving forward 
computer-mediated communication research and investigations into the pragmatics of electronic discourse.

\section{Acknowledgements}

This paper was partly funded by the Spanish Ministry of Science and Innovation (Project reference: FFI2008-04534/FILO).

I would like to express my gratitude to Dr. Nuria Lorenzo-Dus, Dr. Pilar GarcésConejos Blitvich and Dr. Barry Pennock-Speck for their insightful comments on an earlier draft of this paper. Needless to say, any mistakes are my own.

\section{References}

Albelda, Marta, 2007. Componentes de la imagen social (pública) española a través de un análisis lingüístico de entrevistas en medios de comunicación. In: Bou Franch, P., Sopeña Balordi, A.E., Briz Gómez, A. (Eds.), Pragmática, discurso y sociedad. Universitat de València, Valencia, pp. 93-108.

Albert, Stuart, Kessler, Suzanne, 1978. Ending social encounters. Journal of Experimental Social Psychology 14, 541-553.

Androutsopoulos, Jannis, 2006a. Introduction: sociolinguistics and computer-mediated communication. Journal of Sociolinguistics 10(4), 419-438.

Androutsopoulos, Jannis, 2006b. Multilingualism, diaspora, and the internet: codes and identities on German-based diaspora websites. Journal of Sociolinguistics 10(4), 520547.

Baron, Noemi S., 1998. Letters by phone or speech by other means: the linguistics of email. Language and Communication 18, 133-170.

Barron, Anne, 2006. Understanding spam: a macro-textual analysis. Journal of Pragmatics 38, 880-904.

Bou-Franch, Patricia, 2006. Solidarity and deference in Spanish computer-mediated communication: a discourse-pragmatic analysis of students' emails to lecturers. In: Bou Franch, P. (Ed.), Ways into Discourse. Comares, Granada, pp. 61-79.

Bou-Franch, Patricia, Lorenzo-Dus, Nuria, 2008. Natural versus elicited data in crosscultural speech act realisation: the case of requests in Peninsular Spanish and British English. Spanish in Context 5(2), 246-277.

Bravo, Diana, 1999. ¿Imagen 'positive' vs. Imagen 'negativa'? Oralia 2, 155-184. Brown, Penelope, Levinson, Stephen C., 1987. Politeness: Some Universals in Language Usage. Cambridge University Press, Cambridge.

Bunz, Ulla, Campbell, Scott W., 2002. Accommodating politeness indicators in personal electronic mail messages. Paper presented at the Association of Internet Researcher's $3^{\text {rd }}$ Annual Conference. Maastricht, The Netherlands, October 13-16, 2002. http://bunz.comm.fsu.edu/AoIR2002politeness.pdf

Collot, Milena, Belmore, Nancy, 1996. Electronic language: a new variety of English. In: Herring, S. (Ed.), Computer-Mediated Communication: Linguistic, Social and Cross-Cultural Perspectives. John Benjamins, Amsterdam, pp.13-20.

Clarke, Matthew, 2009. The discursive construction of interpersonal relations in an online community of practice. Journal of Pragmatics 41, 2333-2344. 
Crystal, David, 2001. Language and the Internet. Cambridge University Press, Cambridge.

Danet, Brenda, Herring, Susan C., (Eds.) 2003. The Multilingual Internet: Language, Culture, and Communication in Instant Messaging, Email and Chat. Journal of Computer Mediated Communication, 9 (1). (special issue)

http://jcmc.indiana.edu/vol9/issue1/

Danet, Brenda, Herring, Susan C., (Eds.) 2007. The Multilingual Internet: Language, Culture, and Communication Online. Oxford University Press, New York.

De Fina, Anna, Schiffrin, Deborah, Bamberg, Michael, (Eds.) 2006. Discourse and Identity. Cambridge University Press, Cambridge.

De Oliveira, Sandi M., 2003. Breaking conversational norms on a Portuguese user's network: men as adjudicators of politeness. Journal of Computer-Mediated Communication 9 (1). http://jcmc.indiana.edu/vol9/issue1/oliveira.html Drew, Paul, Sorjonen, Marja-Leena, 1997. Institutional dialogue. In: Van Dijk, T.A. (Ed.), Discourse as Social Interaction. Sage,London, pp. 92-118.

Duthler, Kirk W., 2006. The politeness of requests made via email and voicemail: Support for the hyperpersonal model. Journal of Computer-Mediated Communication 11 (2). http://jcmc.indiana.edu/vol11/issue2/duthler.html

Ellison, Nicole B., Steinfield, Charles, Lampe, Cliff, 2007. The benefits of Facebook "friends": social capital and college students' use of online social network sites. Journal of computer-mediated Communication. 12 (4).

http://jcmc.indiana.edu/vol12/issue4/ellison.html

Garcés-Conejos, Pilar, Bou-Franch, Patricia, 2008. Cortesía en las páginas web interactivas. El comercio electrónico. In: Briz, A. et al. (Eds.), Cortesía y Conversación. De lo escrito a lo oral. III Coloquio Internacional del Programa Edice. Filología Española, Universitat de Valencia, Valencia, pp. 468-488.

Graham, Sage L., 2007. Disagreeing to agree: Conflict, (im)politeness and identity in a computer-mediated community. Journal of Pragmatics 39, 742-759.

Hernández-Flores, Nieves, 1999. Politeness ideology in Spanish colloquial conversation: the case of advice. Pragmatics, 9 (1): 37-49.

Herring, Susan C., 1996. Two variants of an electronic message schema. In: Herring, S. (Ed.), Computer-Mediated Communication: Linguistic, Social and Cross-Cultural Perspectives. John Benjamins, Amsterdam, pp. 81-106.

Herring, Susan C., 1999. Interactional coherence in CMC. Journal of Computer Mediated Communication, 4 (4). http://jcmc.indiana.edu/vol4/issue4/herring.html Herring, Susan C., 2000. Gender differences in CMC: findings and implications. The CPSR Newsletter 18 (1). http://www.cpsr.org/issues/womenintech/herring Herring, Susan C., 2003. Gender and power in on-line communication. In: Holmes, J., Meyerhoff, M. (Eds), The Handbook of Language and Gender. Blackwell, Oxford, pp. 202-228.

Herrings, Susan C., 2004. Computer-mediated discourse analysis: an approach to researching online communities. In: Barab, S.A., Kling, R., Gray, J. H. (Eds.), Designing for Virtual Communities in the Service of Learning. Cambridge University Press, Cambridge, 338-376. 
Herring, Susan C., 2007. A faceted classification scheme for computer-mediated discourse. Language@internet 4.

http://www.languageatinternet.de/articles/2007/761/index_html/

Jefferson, Gail, 1972. Side Sequences. In: Sudnow, D. (Ed.), Studies in Social

Interaction. Free Press, New York, pp. 294-338.

Lange, Patricia G., 2007. Publicly private and privately public: social networking on YouTube. Journal of Computer-Mediated Communication 13 (1).

http://jcmc.indiana.edu/vol13/issue1/lange.html

Levinson, Stephen C., 1992. Activity types and language. In: Drew, P., Heritage, J.

(Eds.), Talk at Work. Cambridge University Press, Cambridge, pp. 66-100.

Márquez Reiter, Rosina, Rainey, Isobel, Fulcher, Glenn, 2005. A comparative study of certainty and conventional indirectness: evidence from British English and Peninsular Spanish. Applied Linguistics 26 (1), 1-31.

Maynor, Natalie, 1994. The language of electronic mail: written speech? In: Little, Greta D., Montgomery, Michael (Eds.), Centennial Usage Studies. Alabama University Press, Tuscaloosa, AL, pp. 48-54.

Mills, Sara, 2003. Gender and Politeness. Cambridge University Press, Cambridge.

Pérez Sabater, Carmen, Turney, Ed, Montero Fleta, Begoña, 2008. Orality and literacy, formality and informality in email communication. Ibérica 15, 71-88.

Schegloff, Emmanuel A., Sacks, Harvey. 1973. Opening up Closings. Semiotica 8, 289327.

Scollon, Ron, Scollon, Suzanne W., 1995. Intercultural Communication: A Discourse Approach. Blackwell, Oxford.

Sherblom, John, 1988. Direction, function, and signature in electronic mail. Journal of Business Communication 25 (4), 39-54.

Sinclair, John, Coulthard, Malcolm, 1975. Towards an Analysis of Discourse. Oxford University Press, Oxford.

Spencer-Oatey, Helen, 2000. Culturally Speaking: Managing Rapport through Talk across Cultures. Continuum, London.

Stubbs, Michael, 1983. Discourse Analysis: The Sociolinguistic Analysis of Natural Language. Blackwell, Oxford.

Thomson, Rob, Murachver, Tamar, 2001. Predicting gender from electronic discourse.

British Journal of Social Psychology 40, 193-208.

Van Dijk, Teun A., 1989. Structures of discourse and structures of power.

Communication Yearbook 12, 18-59.

Waldvogel, Joan, 2002. Some features of workplace emails. New Zealand English Journal 16, 42-52.

Waldvogel, Joan ,2007. Greetings and closings in workplace email. Journal of

Computer-Mediated Communication, 12 (2).

http://jcmc.indiana.edu/vol12/issue2/waldvogel.html

Walther, Joseph B., 1996. Computer-mediated communication: impersonal, interpersonal and hyperpersonal interaction. Communication Research 23(1), 3-43. 
Werry, Christopher C., 1996. Linguistic and interactional features of Internet Relay Chat. In: Herring, S.C. (Ed.), Computer-Mediated Communication: Linguistic, Social and Cross-Cultural Perspectives. John Benjamins, Amsterdam, pp. 47-63.

Yates, Simeon J., 1996. Oral and written linguistic aspects of computer conferencing: a corpus based study. In: Herring, S.C. (Ed.), Computer-Mediated Communication:

Linguistic, Social and Cross-Cultural Perspectives. John Benjamins, Amsterdam, pp. 29-46.

Yus, Francisco, 2001. Ciberpragmática. Ariel, Barcelona.

Yus, Francisco, 2007. Towards a pragmatics of weblogs. In: Bou-Franch, P. et al.

(Eds.), Pragmática, discurso y sociedad. Universitat de València, Valencia, pp. 15-33. 